\title{
Genomic prediction for beef fatty acid profile in Nellore cattle
}

Hermenegildo Lucas Justino Chiaia ${ }^{\mathrm{a}, *}$, Elisa Peripoli a , Rafael Medeiros de Oliveira Silva ${ }^{\mathrm{a}}$, Carolyn Aboujaoude ${ }^{\text {a }}$ Fabiele Loise Braga Feitosa ${ }^{\text {a }}$, Marcos Vinicius Antunes de Lemos a , Mariana Piatto Berton ${ }^{\text {a }}$, Bianca Ferreira Olivieri ${ }^{a}$, Rafael Espigolan ${ }^{a}$, Rafael Lara Tonussi ${ }^{a}$, Daniel Gustavo Mansan Gordo ${ }^{\text {a }}$, Tiago Bresolin a , Ana Fabrícia Braga Magalhães a , Gerardo Alves Fernandes Júnior a , Lúcia Galvão de Albuquerque ${ }^{a}$, Henrique Nunes de Oliveira ${ }^{a}$, Joyce de Jesus Mangini Furlan ${ }^{\text {b }}$, Adrielle Mathias Ferrinho ${ }^{b}$, Lenise Freitas Mueller ${ }^{c}$, Humberto Tonhati ${ }^{a}$, Angélica Simone Cravo Pereira ${ }^{\mathrm{b}}$, Fernando Baldi ${ }^{\mathrm{a}}$

\footnotetext{
a Faculdade de Ciências Agrárias e Veterinárias, UNESP, Jaboticabal, SP, 14884-000, Brazil

b Faculdade de Medicina Veterinária e Zootecnia, USP, Pirassununga, SP, 13635-900, Brazil

c Faculdade de Zootecnia e Engenharia de Alimentos, USP, Pirassununga, SP, 13635-900, Brazil
}

\section{A R T I C L E I N F O}

\section{Article history:}

Received 21 July 2016

Received in revised form 14 January 2017

Accepted 7 February 2017

Available online 9 February 2017

\section{Keywords:}

Bos indicus

Lipid profile

Meat quality

Genomic selection

\begin{abstract}
A B S T R A C T
The objective of this study was to compare SNP-BLUP, BayesC $\pi$, BayesC and Bayesian Lasso methodologies to predict the direct genomic value for saturated, monounsaturated, and polyunsaturated fatty acid profile, omega 3 and 6 in the Longissimus thoracis muscle of Nellore cattle finished in feedlot. A total of 963 Nellore bulls with phenotype for fatty acid profiles, were genotyped using the Illumina BovineHD BeadChip (Illumina, San Diego, CA) with 777,962 SNP. The predictive ability was evaluated using cross validation. To compare the methodologies, the correlation between DGV and pseudo-phenotypes was calculated. The accuracy varied from -0.40 to 0.62 . Our results indicate that none of the methods excelled in terms of accuracy, however, the SNP-BLUP method allows obtaining less biased genomic evaluations, thereby; this method is more feasible when taking into account the analyses' operating cost. Despite the lowest bias observed for EBV, the adjusted phenotype is the preferred pseudophenotype considering the genomic prediction accuracies regarding the context of the present study.
\end{abstract}

(c) 2017 Published by Elsevier Ltd.

\section{Introduction}

Nowadays, there is a continuing and growing concern about excessive fat consumption and its impact on human health, especially those from animal sources. The high consumption of saturated fatty acids (SFA) is associated with high serum cholesterol and low density lipoproteins levels (LDL), which are risk factors for the occurrence of cardiovascular diseases (Katan, Zoock, \& Mensink, 1994). The predominant SFA in the cattle meat fat are myristic, palmitic, and stearic fatty acids (FAs) (Lawrie, 2005; Rossato et al., 2009). The polyunsaturated fatty acids (PUFA) present in the beef fat such as linoleic (C18:2n-6) and linolenic (C18:3n-3), and monounsaturated (MUFA) as oleic acid (C18:1n-9), provide protection to the cardiovascular system, once the balanced consumption of them is associated with reduce serum cholesterol and an increase in high density lipoprotein (HDL) (Pensel, 1998; Tapiero, Nguyen-Ba, Couvreur, \& Tew, 2002).

\footnotetext{
* Corresponding author.

E-mail address: chiaia1@yahoo.com.br (H.L.J. Chiaia).
}

Furthermore, the fat presented in ruminants meat is a natural source of conjugated linoleic acid (CLA) isomers (French, O'Riordan, \& Monahan, 2000), which are synthesized in the rumen (Tamminga \& Doreau, 1991) and has favorable effects on human's health, increasing the immunostimulatory, antimutagenic, and antioxidant activities (Ip, 1997). There is a growing market demand for sources of healthier lipid profile, and several strategies have been used to improve the beef FA profile, such as dietary manipulation and animal breeding. In these sense, Cesar et al. (2014) and Aboujaoude et al. (2016) reported that selection for beef FAs profile in Nellore cattle is very feasible, since there is additive genetic variation for most beef fatty acids in Nellore cattle. However, the high cost to obtain the phenotypic information and the fact that this trait can be only obtained after slaughter limits the genetic improvement trough traditional selection. Although the FAs profile is not considered as selection criteria, genomic selection is a relevant tool to increase genetic progress for this trait, because the animal can be evaluated early in life, even at birth, reducing the generation interval and at a low cost.

Several methods have been proposed to predict the genomic breeding values (GEBV) such us SNP-BLUP (Single Nucleotide 
Polymorphisms-Best Linear Unbiased Predictor), LASSO (Least Absolute Shrinkage and Selection Operator) and Bayesian methods. SNP-BLUP assumes a normal distribution for SNP effect, with average equal to zero and common variance for all markers (Meuwissen, Hayes, \& Goddard, 2001). LASSO assumes a double exponential distribution for the SNPs effect (Park \& Casella, 2008; De los Campos et al., 2009). BayesC and Bayes $C \pi$, which considered a variable with binomial distribution that reports whether a marker (SNP) has (1) or not (0) effect on the trait under study, with $\pi$ variable probability to be zero and a normal distribution with probability $1-\pi$, assuming that part of the effect markers follows a normal distribution. The BayesC differs from Bayes $C \pi$ mainly due to the value of $\pi$ being fixed in the first one and estimated from the analyzed data in BayesC $\pi$. All of these methods differ in the assumptions about the genetic model associated with quantitative traits, and the best method is the one that reflects the biological nature of polygenic traits, in terms of genic effects (Resende, Lopes, da Silva, \& Pires, 2008).

Studying an Angus population, Saatchi et al. (2013) concluded that genomic selection for beef FA profile using Bayesian models is feasible. Recently, Onogi et al. (2015) evaluated the predictive ability of genomic selection in FA composition of Japanese Black cattle, using single-step genomic best linear unbiased method. The genomic selection has potential to increase the genetic gain for hard measure traits, as FA profile, however, the most suitable model to evaluate those traits are still being studied. It is important to highlight that in tropical and subtropical regions the indicine breeds are the predominant source of beef and, up to date, there are no studies about genomic selection for beef FA profile in Nellore cattle under tropical conditions. Therefore, the objective of this study was to compare the predictive ability of SNP-BLUP, Bayesian Lasso, BayesC, and BayesC $\pi$ methods for beef FA profile of Nellore cattle finished in feedlot.

\section{Material and methods}

\subsection{Data}

A total of 937 Nellore bulls finished in feedlot for a minimum period of 90 days and slaughtered with an average of 24 months of age, were analyzed. The animals belonged to eight different farms located in the Southeast, Northeast, and Midwest regions of Brazil, which participate in three beef cattle breeding programs (Nellore Qualitas, Paint and Delta Gen). In these breeding programs animals are selected based on growth, finishing, and sexual precocity traits.

Breeding seasons differed among these farms; therefore, calving seasons were concentrated from August to October in some farms and from November to January in others. Weaning was performed at seven months of average age. Animals were raised on grazing conditions using Brachiaria sp. and Panicum sp. forages, and had free access to mineral salt. At approximately 1 year of age, the breeding animals were selected and the remaining animals were kept in feedlot with a forage:concentrate ratio ranging from 50:50 to 70:30, depending on the farm. In general, whole-plant corn or sorghum silage was used as high quality forage; and corn grains and/or sorghum, and soybeans, soybean meal, or sunflower seeds were used as protein concentrate.

The farmers used a mean live weight between 500 and $550 \mathrm{~kg}$ as criteria for slaughtering the animals. The slaughters were carried out in commercials slaughterhouses, in accordance with the Brazilian Federal Inspection Service procedures. After $48 \mathrm{~h}$ post mortem stored between 0 and $2{ }^{\circ} \mathrm{C}$, samples from $2.54 \mathrm{~cm}$ thick were removed from the Longissimus thoracis muscle, between the 12 and 13th ribs from each animal, were placed in plastic bags, and stored at $-80{ }^{\circ} \mathrm{C}$ until further analyses.

\subsection{Fatty acid profile analyses}

The meat FAs were extracted from intramuscular fat of the longissimus thoracis muscle using the method by Folch, Lees, and
Stanley (1957) and the methyl esters were formed according to Kramer et al. (1997). The FA profile in meat was performed at the Meat Science Laboratory (LCC) in the Department of Animal Nutrition and Production at FMVZ/USP.

The FAs were quantified using a gas chromatography (GC-2010 Plus - Shimadzu AOC 20i auto-injector) with a SP-2560 capillary column $(100 \mathrm{~m} \times 0.25 \mathrm{~mm}$ in diameter with $0.02 \mathrm{~mm}$ thickness, Supelco, Bellefonte, PA). The initiating temperature was $70{ }^{\circ} \mathrm{C}$ with gradual warming $\left(13^{\circ} \mathrm{C} \mathrm{min}{ }^{-1}\right)$ up to $175^{\circ} \mathrm{C}$, holding for $27 \mathrm{~min}$, and later a further increase of $4{ }^{\circ} \mathrm{C} \cdot \mathrm{min}^{-1}$ until $215^{\circ} \mathrm{C}$ was reached and held for $31 \mathrm{~min}$. Hydrogen $\left(\mathrm{H}_{2}\right)$ was used as the carrier gas with $40 \mathrm{~cm}^{3} \cdot \mathrm{s}^{-1}$. Fatty acids were identified by comparison of retention time of methyl esters of the samples with standards of FAs C4-C24 (F.A.M.E mix Sigma ${ }^{\circledR}$ ), vaccenic acid (V038-1G, Sigma $\left.{ }^{\circledR}\right)$, linoleic acid (UC-61 M $100 \mathrm{mg}$ ), conjugated linoleic acid (CLA) (UC-60M $100 \mathrm{mg}$, Sigma ${ }^{\circledR}$ ) and tricosanoic acid (Sigma $\AA$ ). Fatty acids were quantified by normalizing the area under the curve of methyl esters using Software GS solution 2.42. Fatty acids content were expressed in percentage of total FA methyl ester quantified.

Based on the quantified acids (Table 1), twenty one FAs (14 individuals and 7 groups of FAs) were selected due to their importance in human health.

\subsection{Genotyping of animals}

Animals were genotyped using the Illumina BovineHD BeadChip (Illumina, San Diego, CA) with 777,962 SNP. Quality control was performed excluding those SNPs markers with unknown genomic position, located on sex chromosomes, monomorphic and markers with minor allele frequency (MAF) less than 0.05 , call rate less than $90 \%$, and excess of heterozygosity. Samples with a call rate less than $90 \%$ were also excluded. After quality control, there were 934 samples (Table 1) and 470,007 SNPs left in the dataset for analyses.

Table 1

Descriptive statistics for fatty acid composition (g/100 g) in Longissimus thoracis muscle from Nellore cattle.

\begin{tabular}{|c|c|c|c|c|}
\hline Trait $^{\mathrm{a}}$ & Chain structure & $\begin{array}{l}\text { Sample } \\
\text { size }\end{array}$ & Mean & $\mathrm{SD}^{\mathrm{b}}$ \\
\hline Myristic acid & $\mathrm{C} 14: 0$ & 867 & 2.13 & 0.54 \\
\hline Palmitic acid & $\mathrm{C} 16: 0$ & 867 & 21.03 & 2.49 \\
\hline Palmitoleic acid & $\mathrm{C} 16: 1$ & 893 & 2.18 & 0.79 \\
\hline Stearic acid & C18:0 & 783 & 13.63 & 3.32 \\
\hline Myristoleic acid & $\mathrm{C} 14: 1$ & 824 & 0.32 & 0.22 \\
\hline Elaidic acid & C18:1 n-9 & 483 & 2.90 & 5.07 \\
\hline Oleic acid & C18:1 & 934 & 17.60 & 14.77 \\
\hline Vaccenic acid & C18:1 n-7 & 878 & 15.05 & 15.33 \\
\hline Linoleic acid & $C 18: 2 n-6$ & 865 & 8.32 & 3.63 \\
\hline Conjugated linoleic acid (CLA) & $\begin{array}{l}\text { C18: } 2 \text { cis }-9 \\
\text { trans }-11\end{array}$ & 727 & 0.26 & 0.11 \\
\hline$\alpha$-Linolenic acid & $C 18: 3 n-3$ & 858 & 0.59 & 0.25 \\
\hline$\gamma$-Linolenic acid & $C 18: 3 n-6$ & 569 & 0.08 & 0.08 \\
\hline Eicosatrienoic acid & $C 20: 3 n-3$ & 862 & 0.49 & 0.19 \\
\hline Docosahexaenoic acid & $C 22: 6 n-3$ & 865 & 0.95 & 0.39 \\
\hline Sum of saturated fatty acid (SFA) & & 868 & 40.66 & 6.12 \\
\hline $\begin{array}{l}\text { Sum of monounsaturated fatty acid } \\
\text { (MUFA) }\end{array}$ & & 868 & 37.55 & 8.05 \\
\hline $\begin{array}{l}\text { Sum of polyunsaturated fatty acid } \\
\text { (PUFA) }\end{array}$ & & 868 & 13.42 & 5.57 \\
\hline Sum of omega $3(n-3)$ & & 868 & 3.81 & 1.55 \\
\hline Sum of omega $6(n-6)$ & & 868 & 9.35 & 4.44 \\
\hline Ratio of n- 6 and $n-3$ (n-6/n-3) & & 868 & 2.54 & 0.97 \\
\hline Ratio of PUFA and SFA (PUFA/SFA) & & 868 & 0.35 & 0.20 \\
\hline $\mathrm{BF}$ & & 1564 & 4.02 & 2.7 \\
\hline IMF & & 1812 & 0.82 & 0.42 \\
\hline
\end{tabular}

a Concentration of fatty acids as a percentage of total fatty acids (FAME) quantified; BF: subcutaneous fat thickness ( $\mathrm{mm}$ ) measured between the 12th and 13th ribs; IMF: total intramuscular fat (\%) in the Longissimus thoracis muscle.

b Standard deviation. 


\subsection{Estimation of SNPs effects and genomic value prediction}

To evaluate the prediction ability within the four different methods (SNP-BLUP, Bayesian Lasso, BayesC, and BayesC $\pi$ ), the cross-validation methodology was used. To perform the cross-validation, the data set was randomly divided into four subsets of similar size and the validation was done in each subset at a time. This process was repeated four times and each group was once considered to be the validation group. An exception has been made for the arachidonic FA, where the cross-validation was composed of two training groups and one validation group due to the reduced data after quality control. The SNP effects were predicted in the training population with known phenotype and genotype. The DGV of animals in the validation set was predicted based on the SNPs effects values estimated on the training population. The Fig. 1 shows the distribution of animals in the training and validation set in each cross-validation design made by principal components analyses which was performed based on the genomic matrix.

The estimated breeding value (EBV) and adjusted phenotype (Yc) were used as pseudophenotypes. The deregressed EBV was not considered as pseudophenotype once close to $50 \%$ of genotyped animals had unknown sire due to the presence of multiple sire mating system. The Yc was adjusted using an animal model considering the fixed effects of contemporary group (crop, farm and management group at yearling) and the covariate age at slaughter in each trait:

$\mathrm{Y}=\mathrm{Xb}+\mathrm{e}$

where $\mathrm{Y}$ is a vector of phenotypic values of given quantitative traits, $\mathrm{b}$ is a vector of fixed effects and covariate, $\mathrm{X}$ is the incidence matrix of fixed effects, and e is the random residual vector with distribution $N \sim\left(0, \sigma_{e}^{2}\right)$.

The EBV was estimated based on BLUP method, using an animal model considering the random additive direct and residual effects, the fixed effects of contemporary group, and the covariate age at slaughter (linear). Single-trait analyses were performed:

$\mathrm{Y}=\mathrm{Xb}+\mathrm{Za}+\mathrm{e}$

where $\mathrm{Y}$ is a vector of phenotypic values of given quantitative traits, $\mathrm{b}$ is a vector of fixed effects and covariate, $a$ is a vector of random animal effect with distribution $\mathrm{N} \sim\left(0, \sigma^{2}\right), \mathrm{X}$ and $\mathrm{Z}$ are incidence matrixes of fixed and random effects, respectively, and e is the random residual vector with distribution $\mathrm{N} \sim\left(0, \sigma_{\mathrm{e}}^{2}\right)$.

The general model for the genomic predictions can be expressed as follows:

$\mathrm{Y}=1 \mu+\mathrm{Xg}+$ ewhere $\mathrm{Y}$ is the vector of pseudo-phenotypes (EBV or $Y c) ; 1$ is the vector of $1 \mathrm{~s} ; \mu$ is the overall mean; $X$ is the matrix $(\mathrm{n} \times \mathrm{p})$ that consists of $\mathrm{p}$ SNPs for $\mathrm{n}$ animals; $\mathrm{g}$ is the random vector of SNP effects, and e is the random residual vector with distribution $\mathrm{N} \sim\left(0, \mathrm{I} \sigma_{\mathrm{e}}^{2}\right)$, where I is an identity matrix and $\sigma_{\mathrm{e}}^{2}$ is the residual matrix. The genotypes were coded as 0, 1, 2 for genotypes AA, Aa (or aA) and aa, respectively.

A chain of 500,000 iterations, with a burn-in period of 80,000 iterations was used for Gibbs sampling, and all samples were stored in the GS3 software developed by Legarra, Ricard, and Filangi (2013). The prior distribution assigned to $\mathrm{g}$ differs depending on the method (Bayesian ridge regression, BayesC or Bayesian Lasso), as explained below:

SNP-BLUP: The SNPs effects are estimated with BLUP a priori assuming a normal distribution and equal variance for all markers. The variances from the SNPs effects were obtained according to Legarra (2014):

$\sigma_{g}^{2}=\frac{\sigma_{u}^{2}}{2 \sum q_{j}\left(1-q_{j}\right)}$

where $\left(\sigma_{u}^{2}\right)$ is the previous genetic variance, $q_{j}$ is the allele frequency at a given marker $j$, and $\mathrm{X}$ is the SNPs matrix.

Bayesian Lasso: This method was proposed by Tibshirani (1996) and modified by Legarra, Granie, and Croiseau (2011). The prior SNPs effects $\left(\mathrm{g}_{\mathrm{i}}\right)$ can be represented by the following equation:

$\operatorname{Pr}\left(\mathrm{g}_{\mathrm{i}} \mid \tau^{2}\right) \sim \mathrm{N}\left(0, \tau_{\mathrm{i}}^{2}\right)$ e $\operatorname{Pr}\left(\tau_{\mathrm{i}}^{2}\right)=\frac{\lambda^{2}}{2} \exp \left(-\lambda^{2}\left|\tau_{\mathrm{i}}^{2}\right|\right)$

The prior SNPs effects distribution is an exponential. Lambda $(\lambda)$ is the sharpness parameter, which determines the distribution of the SNP effect. A priori, $\lambda$ is a gamma distribution between 0 and $10^{7}$. The parameterization consists of the estimation of individual SNPs variance $\left(\tau_{\mathrm{i}}^{2}\right)$, which is conditional on settlement of the $\lambda$ parameter.

BayesC $\pi$ : For this method, which used the $\pi$ estimated from the analyzed data set, an additional variable is included $\left(\delta_{i}\right)$, which informs whether the marker has an effect (1) or not (0). The prior distribution of $\delta$ is binomial, with probability of $\pi$ being zero (no effect). When the probability is $1-\pi$, it is assumed that this portion of the markers with
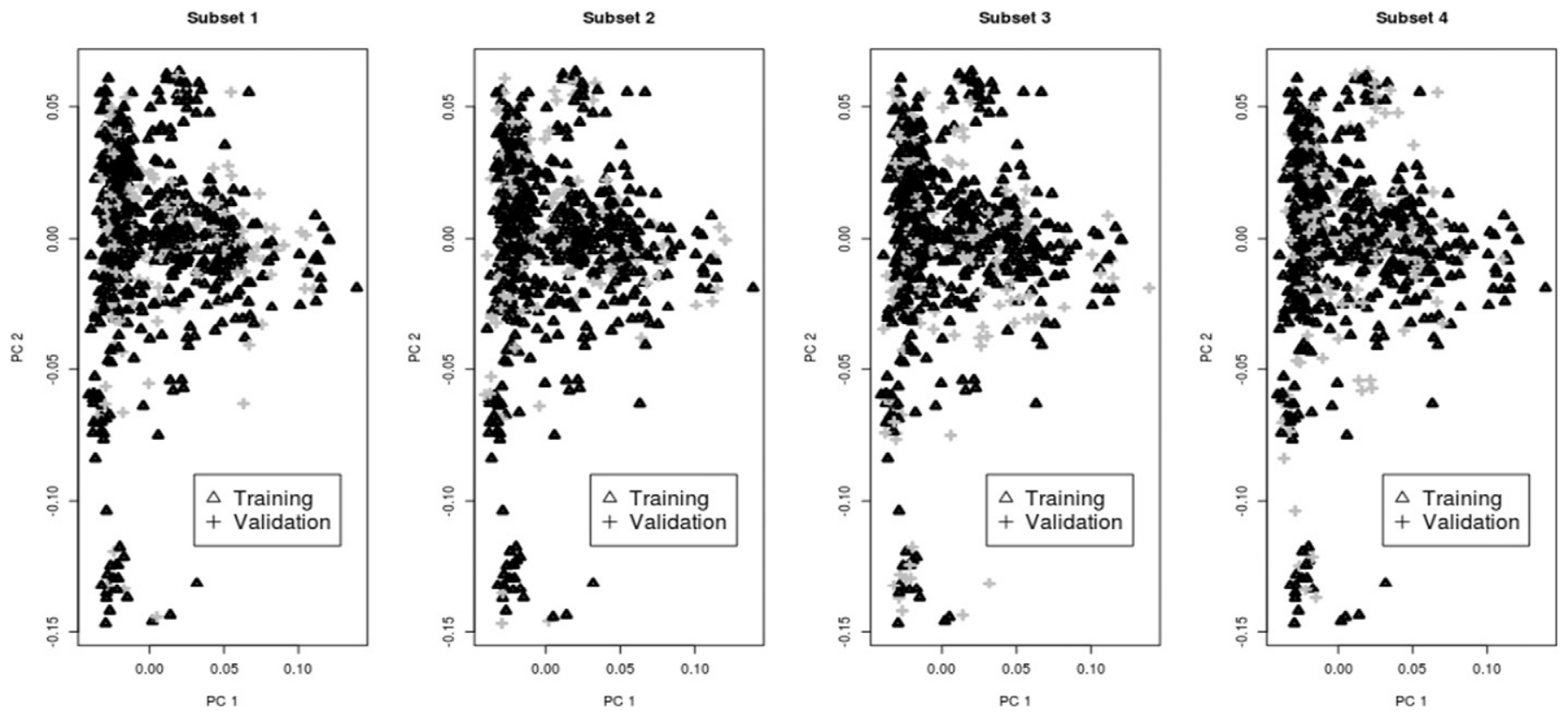

Fig. 1. Distribution of training and validation set in each cross-validation design made by principal components (PC1 and PC2) analyses based on the genomic matrix. 
effect follows a normal distribution. In this method, it is assumed that variance is common to all SNPs, following a scaled inverse chi-squared a priori distribution with $v_{a}$ degrees of freedom and scale parameters $S^{2}{ }_{a}$.

BayesC: This method presents the assumption that $\pi$ is fixed (Kizilkaya, Fernando, \& Garrick, 2010; Legarra, 2014). In the present study, the $\pi$ was fixed at zero.

For all methods, the DGV was predicted from the estimated SNPs effects using the following equation:

$\mathrm{DGV}=\sum_{\mathrm{j}}^{\mathrm{n}} \mathrm{X}_{\mathrm{ij}} \hat{\mathrm{g}}_{\mathrm{i}}$

where $n$ is the number of SNPs; $X_{i}$ is the genotype of animal i for SNP $j$ (coded as 0,1 or 2 ), and $\hat{g}_{j}$ is the estimated SNP substitution effect for SNP $\mathrm{j}$ that was estimated from the training population.

The correlation coefficient between Yc or EBV and DGV were used to evaluate and compare the prediction ability of the methods. The analyses that used Yc as response variable, the prediction accuracy was obtained by dividing the correlation between Yc and DGV by the square root of the heritability $(\mathrm{h})$ of the trait, as described by Legarra, RobertGranié, Manfredi, and Elsen (2008). The linear regression coefficient of the pseudophenotype on DGV was considered to express the bias magnitude of DGV relative to the pseudophenotype. Values close to one are considered the most desirable. Both correlation and bias were used to evaluate and compare the prediction ability of the methods.

\section{Result and discussion}

\subsection{Fatty acid profile}

The descriptive statistics for composition of the most relevant individual SFA, MUFA and PUFA, and for the sum of the SFA, MUFA, PUFA, $\mathrm{n}-3, \mathrm{n}-6, \mathrm{n}-6 / \mathrm{n}-3$ ratio, and PUFA/SFA ratio are presented in Table 1.

Our results agreed with those reported by Kelly, Tume, Newman, and Thompson (2013) and Cesar et al. (2014) who also observed C16:0, C18:0 and C18:1 in the highest concentrations, however, in different proportions as ours (Table 1 ). The difference in FAs proportions observed by these authors could be due to the different degrees of carcass adipose tissue (Wood \& Enser, 1997; Prado, Moreira, Matsushita, \& Souza, 2003), since lower fat deposition can result in higher PUFA and lower oleic acid deposition (Rule, 1997). According to Lawrie (2005), the individual SFAs predominant in cattle meat are C16:0, C14:0 and $\mathrm{C} 18: 0$, as found in this study. The $\mathrm{C} 14: 0$ and $\mathrm{C} 16: 0$ are associated with an increase in circulating LDL cholesterol due to interference with hepatic LDL receptors (Woollett, Spady, \& Dietschy, 1992; Katan et al., 1994).

The MUFAs such as C18:1 and C18:1 n-7, and the PUFA such as linoleic were found in the highest concentrations in this study (Table 1). The C18:1 n-7 is a naturally occurring trans-fat found in red meat, and has been reported as having beneficial health effects on humans (Lock, Horne, Bauman, \& Salter, 2005; Kelly et al., 2013). Compared with other studies, the C18:2 n- 6 concentration obtained in this study was higher (8.32\%), since Prado et al. (2003) and Cesar et al. (2014) observed $3.74 \%$ and $1.60 \%$ for C18:2 n-6 concentration, respectively.

According to Wood and Enser (1997), a potential benefit of feeding diets rich in linolenic acid is that it could lead to an increased synthesis of long-chain PUFA such as eicosapentaenoic and docosahexaenoic acid, which are n-3 FAs involved in decreasing the blood thrombotic tendency. The $\mathrm{n}-3$ concentration (3.81\%) was higher than those reported by Cesar et al. (2014) (0.44\%), Ekine-Dzivenu et al. (2013) (0.18\%), and Prado et al. (2003) (5.39\%). Rossato et al. (2010) showed that zebu breeds genetically have higher levels of higher n-3 FA than Angus meat. The n-6/n-3 ratio was lower than 4.84 found by Cesar et al. (2014), and higher than 1.58 found by Rossato et al. (2010). For human health, the optimal n-6/n-3 ratio ranges from 1 to 4 depending on the disease considered (Simopoulos, 2002).

In the present study, the state of saturation was predominated by SFAs (40.66\%), followed by the MUFAs (37.55\%) and PUFAs (13.42\%). Prado et al. (2003) reported similar results in Nellore breed: 43.93\%, $42.33 \%$ and $12.08 \%$ for SFAs, MUFAs and PUFAs, respectively. However, the quantities reported by these authors were relatively high, and a slightly difference was observed between MUFA and SFA. Pitchford, Deland, Siebert, Malau-Aduliand, and Bottema (2002) and Cesar et al. (2014) also found similar concentrations for SFA (47\%), 47.23\% and 48.34\% for MUFA, in taurine and Nellore breeds, respectively. Beef and lamb meat normally have a low PUFA/SFA ratio due to their biohydrogenation of unsaturated FAs in the rumen and mean values may range largely depending on genetic and non-genetic factors (Smet, Raes, \& Demeyer, 2004).

Prado et al. (2003), Kelly et al. (2013), and Cesar et al. (2014) found a lower proportion of PUFA, $12.08 \%, 1.26 \%$, and $2.87 \%$, respectively, than the one obtained in the present study (13.42\%). This difference is probably due to the high concentration of linoleic FA, as previously explained. Silva, Prado, Matsushita, and Souza (2002) working with crossbred heifers (European x zebu), found on MUFAs the most abundant FAs (40 to 55\%) among all analyzed, with the greatest proportion for oleic. This difference is probably due to the experimental diets used in each study (Silva et al., 2002). Studies have shown that in feedlot finishing systems, Bos taurus meat presents lower percentages of SFA, higher percentages of MUFA, and similar levels of PUFAs compared to Bos indicus meat (Perry, Nicholls, \& Thompson, 1998; Menezes et al., 2009; Rossato et al., 2010; Bressan et al., 2011). According with Feitosa et al. (2016) who worked with the same data set used in this study, the mean \pm SD values for shear force ( $5.17 \pm 1.4$ ), intramuscular fat content $(0.82 \pm 0.42 \%)$ and back fat thickness $(4.02 \pm 2.7 \mathrm{~mm})$ indicated that the beef acceptability could compromised in some international markets. However, the Nellore beef has attributes that are beneficial to human health such as low intramuscular fat content and a beef fatty acid profile with high levels of the n-3 series and an adequate dietary quality based on the n-6/n-3 and PUFA/SFA ratios.

\subsection{Genomic predictive ability}

The accuracy of pedigree based BLUP evaluation were lower compared to SNP-BLUP model, varying from 14 to $62 \%$ and from 3 to $82 \%$, when the EBV and Yc were used as pseudophenotype, respectively. These results demonstrated that the genomic prediction would lead to an increase in accuracy above that achieved with standard BLUP. Wiggans, Vanraden, and Cooper (2011) reported reliability gains for milk traits above parent average ranging in young bulls from 2.7 to 47.6 percentage units for Holsteins, 9.6 to 29.2 percentage units for Jerseys, and 3.0 to 25.8 percentage units for Brown Swiss. In beef cattle, Garrick (2011) stated that genomic prediction offers accuracies that exceed those of pedigree-based parent average of young selection candidates, and it can be equivalent to progeny tests based on up to 10 offspring.

Comparing the prediction methods using different pseudophenotypes for the SFA (Table 2), the Yc showed the best prediction ability. When comparing the prediction methods with the best pseudophenotype, the SNP-BLUP showed the best prediction ability for the myristic and palmitic FA, while the Bayesian methods were superior for stearic and sum of SFA.

When using different pseudophenotypes to compare MUFA (Table 3 ), the Yc showed the best prediction ability for the elaidic and total sum of MUFA; with the exception for myristic, palmitoleic, and vaccenic FA. For the SNP-BLUP method, when the Yc was superior or close, it showed the best prediction ability; regarding the EBV as the best pseudophenotype for the myristic FA, the SNP-BLUP was superior to Bayesian methods. 
Table 2

Accuracies of genomic predictions measured by Pearson's correlation between pseudophenotype and direct genomic breeding values ( $\left.\mathrm{r}_{(\mathrm{Yi}, \mathrm{DGV})}\right)$, and standard error (SE) for beef saturated fatty acids of Nellore cattle based on different methods.

\begin{tabular}{|c|c|c|c|c|c|c|c|c|c|}
\hline \multirow{3}{*}{$\begin{array}{l}\text { Fatty acid } \\
(\mathrm{g} / 100 \mathrm{~g})\end{array}$} & \multirow{3}{*}{$\begin{array}{l}\text { Type } \\
\text { Yc } \\
\end{array}$} & \multicolumn{8}{|c|}{$\mathrm{r}_{(\mathrm{Yi}, \mathrm{DGV})}{ }^{\mathrm{a}} \pm(\mathrm{SE})$} \\
\hline & & \multicolumn{2}{|c|}{ SNP-BLUP } & \multicolumn{2}{|c|}{$\begin{array}{l}\text { Bayesian } \\
\text { LASSO }\end{array}$} & \multicolumn{2}{|l|}{ BayesC } & \multicolumn{2}{|c|}{ BayesC $\pi$} \\
\hline & & 0.30 & $(0.03)$ & 0.19 & $(0.07)$ & 0.15 & $(0.08)$ & 0.15 & $(0.10)$ \\
\hline & EBV & 0.20 & $(0.02)$ & 0.16 & $(0.06)$ & 0.10 & $(0.07)$ & 0.16 & $(0.08)$ \\
\hline \multirow[t]{2}{*}{$\mathrm{C} 16: 0$} & Yc & 0.25 & $(0.06)$ & 0.13 & $(0.06)$ & 0.15 & $(0.03)$ & 0.19 & $(0.10)$ \\
\hline & EBV & 0.14 & $(0.03)$ & 0.07 & $(0.04)$ & 0.03 & $(0.05)$ & 0.09 & $(0.04)$ \\
\hline \multirow[t]{2}{*}{ C18:0 } & Yc & 0.16 & $(0.14)$ & 0.28 & $(0.03)$ & 0.13 & $(0.13)$ & 0.19 & $(0.15)$ \\
\hline & EBV & 0.05 & $(0.03)$ & 0.07 & $(0.03)$ & -0.01 & $(0.04)$ & 0.03 & $(0.04)$ \\
\hline \multirow[t]{2}{*}{ Sum of SFA } & Yc & 0.20 & $(0.19)$ & 0.12 & $(0.07)$ & 0.17 & $(0.11)$ & 0.24 & $(0.12)$ \\
\hline & EBV & 0.17 & $(0.04)$ & 0.04 & $(0.05)$ & 0.10 & $(0.02)$ & 0.09 & $(0.03)$ \\
\hline
\end{tabular}

${ }^{a}$ For the Yc as response variable, $\left.r_{(y i, D G V}\right)$ was divided by the square root of heritability of the trait; Yc phenotype adjusted for fixed effects, EBV estimated breeding value, SFA saturated fatty acid.

The Yc for PUFA (Table 4) revealed similar prediction ability as those revealed by EBV for almost all FA, with an exception for $\alpha$-linolenic acid and CLA in which the EBV was superior. This exception, however, must consider the reduced sample size, which might limit the accuracy. SNPBLUP and Bayesian methods showed close results regarding the prediction ability for linoleic, $\alpha$-linolenic, docosahexaenoic, sum of n-6 and n3, n-6/n-3 ratio, eicosatrienoic, PUFA/SFA ratio, and sum of PUFA; while the SNP-BLUP method showed better prediction ability for CLA and $\gamma$ linoleic FA.

Overall, when using EBV in reduced samples size such as C14:0, C16:0, C14:1, linoleic, C18:2 cis-9 trans-11, and C18:3 n-3, the SNPBLUP method showed superiority to Bayesian methods for almost all FA. On the other hand, when considering the Yc, the opposite was observed. Different from the result obtained in this study for Bayesian methods, Saatchi et al. (2013) observed high accuracies in Angus cattle for C14:0 and C16:0. Neves et al. (2014) disclosed that Lasso and BayesC methods were superior to SNP-BLUP method in growth traits for 685 Nellore animals, suggesting the segregation of major genes effect for the studied traits as the reason for the superiority of Bayesian methods.

The divergence between studies suggests that the difference within the methods is due to the genetic architecture of the trait i.e., the accuracy tends to increase as the model adjusts itself to the genetic architecture of the trait (Lund, Sahana, Koning, Su, \& Carlborg, 2009). For traits that are affected by moderate to major genes effect, higher accuracies can be reached through Bayesian methods (Neves et al., 2014). Traits that are controlled by many genes with small effects, the SNP-BLUP method shows better prediction ability (Clark, Hickey, \& van der Werf, 2011). Nonetheless, Daetwyler, Pong-Wong, Villanueva, and Woolliams (2010) in a simulation study proposed that the Bayesian method's superiority over the SNP-BLUP methods depends on the number of QTL for the trait. If the QTL number is higher than the effective number of chromosomal segments, the SNP-BLUP method shows better or similar prediction ability than Bayesian methods. In addition, the computational time displays an advantage of SNP-BLUP methods, Colombani et al. (2013) and Neves et al. (2014) figured out that Bayesian methods were less time effective.

In terms of magnitude of the observed results, Bolormaa et al. (2013) reported that although the prediction accuracy is still low in beef cattle compared with dairy cattle, this should not be a limiting, since genomic selection can improve traits which are difficult to measure, such as beef FA profile. Although the results presented here have a low to moderate accuracy, when considering the high cost of measurement and the difficulty of selecting animals for meat quality traits such as FA, the implementation of genomic selection in Nellore might be a viable alternative.

\subsection{Inflation/deflation of genomic prediction}

By considering the Yc for SFA (Table 5), the regression coefficient estimates $\left(b_{(Y c, D G V)}\right)$ for both the Bayesian methods as well as for the SNPBLUP were, on average, below to one for all FA. When considering EBV, the Bayesian methods (LASSO and BayesC $\pi$ ) showed a regression coefficient $\left(b_{(E B V, D G V)}\right)$ close to one for $C 14: 0$, and lower to one for $\mathrm{C16}: 0$, C18:0 and sum of SFA, being inflated. The SNP-BLUP method showed $\left(b_{(E B V, D G V)}\right)$ superior to one for sum of SFA, being deflated.

When considering the Yc for MUFA, the $b_{(Y c, D G V)}$ (Table 6) were lower to one for all considered FA and for all methods, being inflated. Considering EBV, $\mathrm{b}_{(\mathrm{EBV}, \mathrm{DGV})}$ estimate were inflated in all analyzed methods for C16:1, C18:1 n-9, C18:1 n-7, and sum of MUFA. Estimate were deflated for C14:1 using the SNP-BLUP method, and inflated for C18:1 using Bayesian methods.

The $b_{(Y c, D G V)}$ estimate for PUFA (Table 7) considering the Yc were, on average, lower to one when inflated; except for C18:2 cis-9 trans-11, C18:3 n-6, C20:3 n-3, and PUFA/SFA ratio in which values were higher than one, being deflated. Considering EBV, the $b_{(E B V, G)}$ estimate using SNP-BLUP method were close to one for C18:2 n-6, C18:2 cis-9 trans11, C18:3 n-3, C20:3 n-3, C22:6 n-3, sum of n-3 and n-6, and n-6/n-3 ratio; and lower to one for C18:3 n-6, and superior to one for sum of PUFA. Using Bayesian methods, estimate were close to one for C18:2 cis-9 trans-11, C22:6 n-3, sum of n-3 and n-6, and PUFA; deflated for PUFA/SFA ratio, and inflated for C18:2 n-6, C18:3 n-3 and C18:3 n-6, and $\mathrm{C} 20: 3 \mathrm{n}-3$.

Overall, the SNP-BLUP method demonstrated a regression coefficient estimate closest to one than Bayesian methods, obtaining a less biased estimate, which favors its adoption in genetic selection for FA profile in Nellore meat. When the predictions are deflated and higher than one, in practice, the difference between progenies from selected

Table 3

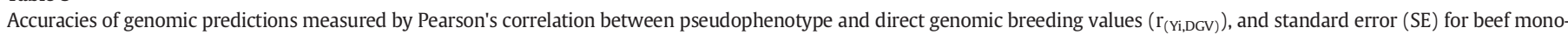
unsaturated fatty acids of Nellore cattle based on different methods.

\begin{tabular}{|c|c|c|c|c|c|c|c|c|c|}
\hline \multirow{2}{*}{$\begin{array}{l}\text { Fatty acid } \\
(\mathrm{g} / 100 \mathrm{~g})\end{array}$} & \multirow[t]{2}{*}{ Type } & \multicolumn{8}{|c|}{$\mathrm{r}_{(\mathrm{Yi}, \mathrm{DGV})}{ }^{\mathrm{a}} \pm(\mathrm{SE})$} \\
\hline & & \multicolumn{2}{|c|}{ SNP-BLUP } & \multicolumn{2}{|c|}{ Bayesian LASSO } & \multicolumn{2}{|l|}{ BayesC } & \multicolumn{2}{|l|}{ BayesC $\pi$} \\
\hline \multirow[t]{2}{*}{ C14:1 } & Yc & 0.03 & $(0.03)$ & -0.02 & $(0.08)$ & 0.08 & $(0.06)$ & -0.01 & $(0.06)$ \\
\hline & EBV & 0.42 & $(0.03)$ & 0.02 & $(0.02)$ & 0.10 & $(0.02)$ & 0.05 & $(0.01)$ \\
\hline \multirow[t]{2}{*}{ C16:1 } & Yc & -0.23 & $(0.23)$ & -0.37 & $(0.13)$ & -0.54 & $(0.25)$ & -0.50 & $(0.33)$ \\
\hline & EBV & 0.03 & $(0.03)$ & -0.01 & $(0.06)$ & 0.00 & $(0.04)$ & 0.09 & $(0.01)$ \\
\hline \multirow[t]{2}{*}{ C18:1 n-9 } & Yc & 0.12 & $(0.12)$ & 0.11 & $(0.04)$ & 0.13 & $(0.05)$ & 0.10 & $(0.06)$ \\
\hline & EBV & 0.07 & $(0.04)$ & 0.00 & $(0.03)$ & 0.02 & $(0.06)$ & 0.06 & $(0.01)$ \\
\hline \multirow[t]{2}{*}{ C18:1 } & Yc & 0.33 & $(0.07)$ & 0.34 & $(0.15)$ & 0.33 & $(0.02)$ & 0.32 & $(0.06)$ \\
\hline & EBV & 0.16 & $(0.05)$ & 0.09 & $(0.04)$ & 0.07 & $(0.05)$ & 0.09 & $(0.04)$ \\
\hline \multirow[t]{2}{*}{ C18:1 n-7 } & Yc & 0.14 & $(0.05)$ & 0.04 & $(0.05)$ & -0.06 & $(0.08)$ & -0.11 & $(0.05)$ \\
\hline & EBV & 0.13 & $(0.04)$ & 0.03 & $(0.03)$ & -0.01 & $(0.06)$ & 0.06 & $(0.04)$ \\
\hline \multirow[t]{2}{*}{ Sum of MUFA } & Yc & 0.12 & $(0.03)$ & 0.10 & $(0.02)$ & 0.13 & $(0.05)$ & 0.07 & $(0.04)$ \\
\hline & EBV & 0.07 & $(0.02)$ & 0.10 & $(0.02)$ & 0.06 & $(0.03)$ & 0.05 & $(0.03)$ \\
\hline
\end{tabular}

${ }^{a}$ For the Yc as response variable, $\mathrm{r}_{(\mathrm{yi}, \mathrm{DGV})}$ was divided by the square root of heritability of the trait; Yc phenotype adjusted for fixed effects, EBV estimated breeding value, MUFA monounsaturated fatty acid. 
Table 4

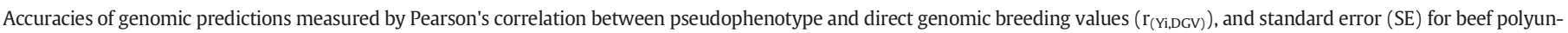
saturated fatty acids of Nellore cattle based on different methods.

\begin{tabular}{|c|c|c|c|c|c|c|c|c|c|}
\hline \multirow{3}{*}{$\begin{array}{l}\text { Fatty acid } \\
(\mathrm{g} / 100 \mathrm{~g})\end{array}$} & \multirow{3}{*}{$\begin{array}{l}\text { Type } \\
\text { Yc }\end{array}$} & \multicolumn{8}{|c|}{$\underline{r}_{(\mathrm{Yi}, \mathrm{DGV})}{ }^{\mathrm{a}} \pm(\mathrm{SE})$} \\
\hline & & \multicolumn{2}{|c|}{ SNP-BLUP } & \multicolumn{2}{|c|}{ Bayesian LASSO } & \multicolumn{2}{|l|}{ BayesC } & \multicolumn{2}{|c|}{ BayesC $\pi$} \\
\hline & & 0.25 & $(0.10)$ & 0.23 & $(0.06)$ & 0.22 & $(0.06)$ & 0.12 & $(0.11)$ \\
\hline & EBV & 0.21 & $(0.02)$ & 0.13 & $(0.06)$ & 0.11 & $(0.06)$ & 0.11 & $(0.07)$ \\
\hline \multirow[t]{2}{*}{ C18:2 cis- 9 trans -11} & Yc & 0.13 & $(0.06)$ & -0.11 & $(0.13)$ & -0.04 & $(0.09)$ & -0.07 & $(0.10)$ \\
\hline & EBV & 0.21 & $(0.02)$ & 0.08 & $(0.04)$ & 0.10 & $(0.01)$ & 0.18 & $(0.03)$ \\
\hline \multirow[t]{2}{*}{$C 18: 3 n-3$} & Yc & -0.01 & $(0.09)$ & 0.00 & $(0.05)$ & 0.06 & $(0.07)$ & -0.03 & $(0.04)$ \\
\hline & EBV & 0.14 & $(0.01)$ & 0.07 & $(0.05)$ & 0.06 & $(0.03)$ & 0.07 & $(0.05)$ \\
\hline \multirow[t]{2}{*}{$C 18: 3 n-6$} & Yc & -0.02 & $(0.04)$ & -0.05 & $(0.06)$ & 0.10 & $(0.03)$ & 0.09 & $(0.01)$ \\
\hline & EBV & 0.01 & $(0.01)$ & 0.00 & $(0.05)$ & 0.08 & $(0.03)$ & 0.05 & $(0.04)$ \\
\hline \multirow{2}{*}{$C 20: 3 n-3$} & Yc & -0.06 & $(0.12)$ & 0.13 & $(0.06)$ & 0.12 & $(0.04)$ & 0.19 & $(0.08)$ \\
\hline & EBV & 0.12 & $(0.03)$ & 0.06 & $(0.05)$ & 0.09 & $(0.03)$ & 0.10 & $(0.03)$ \\
\hline \multirow[t]{2}{*}{$C 22: 6 n-3$} & Yc & 0.10 & $(0.08)$ & 0.18 & $(0.11)$ & 0.15 & $(0.13)$ & 0.18 & $(0.12)$ \\
\hline & EBV & 0.36 & $(0.18)$ & 0.36 & $(0.19)$ & 0.33 & $(0.22)$ & 0.31 & $(0.21)$ \\
\hline \multirow[t]{2}{*}{ Sum of n-3 } & Yc & 0.12 & $(0.02)$ & 0.24 & $(0.11)$ & 0.11 & $(0.12)$ & 0.25 & $(0.10)$ \\
\hline & EBV & 0.07 & $(0.06)$ & 0.07 & $(0.06)$ & 0.05 & $(0.07)$ & 0.12 & $(0.05)$ \\
\hline \multirow[t]{2}{*}{ Sum of n-6 } & Yc & 0.32 & $(0.09)$ & 0.26 & $(0.07)$ & 0.34 & $(0.07)$ & 0.24 & $(0.08)$ \\
\hline & EBV & 0.22 & $(0.03)$ & 0.14 & $(0.08)$ & 0.22 & $(0.03)$ & 0.15 & $(0.07)$ \\
\hline \multirow[t]{2}{*}{$n-6 / n-3$} & Yc & -0.07 & $(0.12)$ & -0.02 & $(0.06)$ & -0.12 & $(0.15)$ & 0.19 & $(0.06)$ \\
\hline & EBV & 0.11 & $(0.05)$ & -0.02 & $(0.01)$ & 0.05 & $(0.05)$ & 0.07 & $(0.05)$ \\
\hline \multirow[t]{2}{*}{ Sum of PUFA } & Yc & 0.50 & $(0.13)$ & 0.45 & $(0.12)$ & 0.56 & $(0.07)$ & 0.48 & $(0.10)$ \\
\hline & EBV & 0.24 & $(0.03)$ & 0.15 & $(0.08)$ & 0.16 & $(0.07)$ & 0.15 & $(0.09)$ \\
\hline \multirow[t]{2}{*}{ PUFA/SFA } & Yc & 0.28 & $(0.15)$ & 0.17 & $(0.13)$ & 0.21 & $(0.12)$ & 0.13 & $(0.17)$ \\
\hline & EBV & 0.32 & $(0.14)$ & 0.32 & $(0.15)$ & 0.33 & $(0.17)$ & 0.32 & $(0.15)$ \\
\hline
\end{tabular}

${ }^{\mathrm{a}}$ For the Yc as response variable, $\mathrm{r}_{(\mathrm{yi}, \mathrm{DGV})}$ was divided by the square root of heritability of the trait, Yc phenotype adjusted for fixed effects, EBV estimated breeding value, SFA saturated

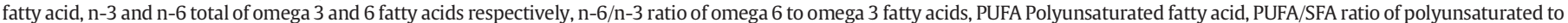
saturated fatty acid.

animals are expected to be greater than those predicted by DGV, and the opposite occurs when the predictor is inflated. Considering pseudophenotype, the EBV exhibited the less biased regression coefficient estimate regarding the Yc. Different from our results, a resemblance between the Bayesian Ridge Regression model, BayesC, and Lasso were reported by Fernandes Júnior et al. (2016) in Nellore cattle for ribeye area, subcutaneous fat, and hot carcass weight.

The differences regarding the pseudophenotype are in agreement with the literature (Boddhireddy et al., 2014; Morota, Boddhireddy, Vukasinovic, Gianola, \& Denise, 2014). Genomic selection studies for novel traits in beef cattle (Silva et al., 2016; Fernandes Júnior et al., 2016), such as feed efficiency and beef quality traits, reported higher genomic prediction ability for adjusted phenotypic used as pseudo-phenotypes over EBV obtained from traditional BLUP. In beef cattle, the EBV obtained from BLUP model in general is less appropriated due to poor pedigree structure and small training population. These results obtained in this study were in accordance with Fernandes Júnior et al. (2016), whom indicated the Yc instead of EBV as pseudophenotype in genomic prediction for highly heritable traits, in spite of the lower biased observed when using EBV.

Table 5

Regression coefficient of the pseudophenotype on direct genomic breeding values $\left(\mathrm{b}_{(\mathrm{Yi}, \mathrm{DGV})}\right)$ and standard error (SE) for beef saturated fatty acids of Nellore cattle based on different methods.

\begin{tabular}{|c|c|c|c|c|c|c|c|c|c|}
\hline \multirow{3}{*}{$\begin{array}{l}\text { Fatty acid } \\
(\mathrm{g} / 100)\end{array}$} & \multirow{3}{*}{$\begin{array}{l}\text { Type } \\
\\
\text { Yc }\end{array}$} & \multicolumn{8}{|c|}{$\mathrm{b}_{(\mathrm{Yi}, \mathrm{DGV})} \pm(\mathrm{SE})$} \\
\hline & & \multicolumn{2}{|c|}{ SNP-BLUP } & \multicolumn{2}{|c|}{$\begin{array}{l}\text { Bayesian } \\
\text { LASSO }\end{array}$} & \multicolumn{2}{|c|}{ BayesC } & \multicolumn{2}{|c|}{ BayesC $\pi$} \\
\hline & & 0.40 & $(0.04)$ & 0.19 & $(0.10)$ & 0.18 & $(0.10)$ & 0.20 & $(0.11)$ \\
\hline & EBV & 0.47 & $(0.05)$ & 0.99 & $(0.70)$ & 0.30 & $(0.17)$ & 0.82 & $(0.53)$ \\
\hline \multirow[t]{2}{*}{ C16:0 } & Yc & 0.36 & $(0.12)$ & 0.12 & $(0.05)$ & 0.12 & $(0.05)$ & 0.17 & $(0.06)$ \\
\hline & EBV & 0.56 & $(0.10)$ & 0.38 & $(0.26)$ & 0.17 & $(0.11)$ & 0.33 & $(0.21)$ \\
\hline \multirow[t]{2}{*}{ C18:0 } & Yc & 0.32 & $(0.09)$ & 0.07 & $(0.02)$ & 0.04 & $(0.02)$ & 0.07 & $(0.02)$ \\
\hline & EBV & 0.24 & $(0.05)$ & 0.01 & $(0.00)$ & 0.01 & $(0.00)$ & 0.03 & $(0.02)$ \\
\hline \multirow[t]{2}{*}{ Sum of SFA } & Yc & 0.17 & $(0.07)$ & 0.10 & $(0.07)$ & 0.10 & $(0.07)$ & 0.15 & $(0.06)$ \\
\hline & EBV & 1.12 & $(0.24)$ & 0.47 & $(0.47)$ & 0.22 & (0.11) & 0.59 & (0.37) \\
\hline
\end{tabular}

Yc phenotype adjusted for fixed effects, EBV estimated breeding value, SFA saturated fatty acid.
Overall, regarding the accuracies, the methods were similar and in agreement with the literature (Moser, Tier, Crump, Khatkar, \& Raadsma, 2009; De Los Campos, Hickey, Pong-Wong, Daetwyler, \& Calus, 2013; Fernandes Júnior et al. (2016). According to De los Campos et al. (2013), studies using real data do not always reveal relevant differences between methods, which can be attributed to the large number of regression coefficients that need to be inferred from a small number of samples $(\mathrm{n}<\mathrm{p})$. Another factor that could explain the similarity of results across the methods is the complex nature of the traits studied. According to Daetwyler, Calus, Pong-Wong, De Los Campos, and Hickey (2013), different methods tend to show similar predictive ability when the traits are affected by many small-effect loci.

Beef fat composition could be viewed in a more favorably standpoint for human health if effective approaches could be applied to decrease beef SFA content, while increasing the concentration of beneficial FA, such as PUFA, especially n-3 and C18:2 cis-9 trans-11. Thus, genomic information can be used to reduce SFA concentration in meat, mainly for

\section{Table 6}

Regression coefficient of the pseudophenotype on direct genomic breeding values $\left(\mathrm{b}_{(\mathrm{Yi}, \mathrm{DGV})}\right)$ and standard error (SE) for beef monounsaturated fatty acids of Nellore cattle based on different methods.

\begin{tabular}{|c|c|c|c|c|c|c|c|c|c|}
\hline \multirow{3}{*}{$\begin{array}{l}\text { Fatty acid } \\
(\mathrm{g} / 100 \mathrm{~g})\end{array}$} & \multirow{3}{*}{$\begin{array}{l}\text { Type } \\
\text { Yc }\end{array}$} & \multicolumn{8}{|c|}{$\mathrm{b}_{(\mathrm{Yi}, \mathrm{DGV})} \pm(\mathrm{SE})$} \\
\hline & & \multicolumn{2}{|c|}{ SNP-BLUP } & \multicolumn{2}{|c|}{$\begin{array}{l}\text { Bayesian } \\
\text { LASSO }\end{array}$} & \multicolumn{2}{|c|}{ BayesC } & \multicolumn{2}{|c|}{ BayesC $\pi$} \\
\hline & & 0.30 & $(0.11)$ & 0.07 & $(0.02)$ & 0.12 & $(0.03)$ & 0.06 & $(0.02)$ \\
\hline & EBV & 1.65 & $(0.18)$ & 0.01 & $(0.00)$ & 0.03 & $(0.01)$ & 0.02 & $(0.00)$ \\
\hline \multirow[t]{2}{*}{ C16:1 } & Yc & 0.16 & $(0.11)$ & 0.06 & $(0.02)$ & 0.10 & $(0.04)$ & 0.10 & $(0.05)$ \\
\hline & EBV & 0.55 & $(0.20)$ & 0.44 & $(0.25)$ & 0.08 & $(0.04)$ & 0.33 & $(0.26)$ \\
\hline \multirow[t]{2}{*}{ C18:1 n-9 } & Yc & 0.34 & $(0.06)$ & 0.07 & $(0.02)$ & 0.07 & $(0.03)$ & 0.07 & $(0.03)$ \\
\hline & EBV & 0.68 & $(0.18)$ & 0.02 & $(0.00)$ & 0.03 & $(0.01)$ & 0.03 & $(0.00)$ \\
\hline \multirow[t]{2}{*}{ C18:1 } & Yc & 0.30 & $(0.10)$ & 0.08 & $(0.07)$ & 0.08 & $(0.02)$ & 0.08 & $(0.04)$ \\
\hline & EBV & 3.43 & (1.19) & 1.74 & (1.47) & 0.55 & $(0.34)$ & 1.07 & $(0.49)$ \\
\hline \multirow[t]{2}{*}{ C18:1 n-7 } & Yc & 0.13 & $(0.04)$ & 0.04 & $(0.02)$ & 0.07 & $(0.03)$ & 0.05 & $(0.02)$ \\
\hline & EBV & 0.77 & $(0.17)$ & 0.02 & $(0.01)$ & 0.01 & $(0.00)$ & 0.02 & $(0.01)$ \\
\hline \multirow[t]{2}{*}{ Sum of MUFA } & Yc & 0.13 & $(0.03)$ & 0.09 & $(0.04)$ & 0.10 & $(0.04)$ & 0.08 & $(0.04)$ \\
\hline & EBV & 0.37 & $(0.11)$ & 0.38 & $(0.21)$ & 0.15 & $(0.08)$ & 0.33 & $(0.18)$ \\
\hline
\end{tabular}

Yc phenotype adjusted for fixed effects, EBV estimated breeding value, MUFA monounsaturated fatty acid. 
Table 7

Regression coefficient of the pseudo-phenotype on direct genomic breeding values $\left(b_{(\mathrm{Yi}, \mathrm{DGV})}\right)$ and standard error (SE) for beef polyunsaturated fatty acids of Nellore cattle based on different methods.

\begin{tabular}{|c|c|c|c|c|c|c|c|c|c|}
\hline \multirow{3}{*}{$\begin{array}{l}\text { Fatty acid } \\
(\mathrm{g} / 100 \mathrm{~g})\end{array}$} & \multirow{3}{*}{$\begin{array}{l}\text { Type } \\
\text { Yc }\end{array}$} & \multicolumn{8}{|c|}{$\mathrm{b}_{(\mathrm{Yi}, \mathrm{DGV})} \pm(\mathrm{SE})$} \\
\hline & & \multicolumn{2}{|c|}{ SNP-BLUP } & \multicolumn{2}{|c|}{$\begin{array}{l}\text { Bayesian } \\
\text { LASSO }\end{array}$} & \multicolumn{2}{|c|}{ BayesC } & \multicolumn{2}{|c|}{ BayesC $\pi$} \\
\hline & & 0.31 & $(0.14)$ & 0.17 & $(0.07)$ & 0.16 & $(0.07)$ & 0.15 & $(0.07)$ \\
\hline & EBV & 1.13 & $(0.17)$ & 0.72 & $(0.51)$ & 0.30 & $(0.19)$ & 0.61 & $(0.42)$ \\
\hline C18:2 cis-9 & Yc & 5.51 & $(2.14)$ & 0.12 & $(0.03)$ & 0.09 & $(0.03)$ & 0.11 & $(0.03)$ \\
\hline trans-11 & EBV & 1.59 & $(0.24)$ & 0.44 & $(0.29)$ & 0.17 & $(0.09)$ & 0.79 & $(0.31)$ \\
\hline \multirow{2}{*}{$C 18: 3 n-3$} & Yc & 0.95 & $(0.38)$ & 0.05 & $(0.02)$ & 0.07 & $(0.02)$ & 0.05 & $(0.01)$ \\
\hline & EBV & 0.83 & $(0.13)$ & 0.51 & $(0.36)$ & 0.16 & $(0.09)$ & 0.44 & $(0.30)$ \\
\hline \multirow[t]{2}{*}{$C 18: 3 n-6$} & Yc & 1.18 & $(1.04)$ & 0.06 & $(0.04)$ & 0.05 & $(0.02)$ & 0.07 & $(0.03)$ \\
\hline & EBV & 0.07 & $(0.04)$ & 0.04 & $(0.01)$ & 0.05 & $(0.02)$ & 0.08 & $(0.06)$ \\
\hline \multirow[t]{2}{*}{$C 20: 3 n-3$} & Yc & 1.69 & $(0.30)$ & 0.08 & $(0.03)$ & 0.30 & $(0.23)$ & 0.11 & $(0.04)$ \\
\hline & EBV & 0.83 & $(0.23)$ & 0.56 & $(0.45)$ & 0.22 & $(0.14)$ & 0.58 & $(0.32)$ \\
\hline \multirow[t]{2}{*}{$C 22: 6 n-3$} & Yc & 0.58 & $(0.31)$ & 0.19 & $(0.11)$ & 0.20 & $(0.10)$ & 0.19 & $(0.11)$ \\
\hline & EBV & 1.59 & $(0.51)$ & 1.40 & $(0.62)$ & 0.66 & $(0.32)$ & 1.19 & $(0.53)$ \\
\hline \multirow[t]{2}{*}{ Sum of n-3 } & Yc & 0.14 & $(0.02)$ & 0.13 & $(0.07)$ & 0.09 & $(0.08)$ & 0.14 & $(0.07)$ \\
\hline & EBV & 0.75 & $(0.55)$ & 0.75 & $(0.55)$ & 0.23 & $(0.17)$ & 0.88 & $(0.43)$ \\
\hline \multirow[t]{2}{*}{ Sum of n-6 } & Yc & 0.40 & $(0.13)$ & 0.22 & $(0.09)$ & 0.25 & $(0.07)$ & 0.21 & $(0.09)$ \\
\hline & EBV & 1.11 & $(0.13)$ & 0.76 & $(0.46)$ & 1.11 & $(0.13)$ & 0.60 & $(0.35)$ \\
\hline \multirow[t]{2}{*}{$n-6 / n-3$} & Yc & 0.18 & $(0.06)$ & 0.04 & $(0.01)$ & 0.10 & $(0.04)$ & 0.07 & $(0.01)$ \\
\hline & EBV & 0.90 & $(0.24)$ & 0.01 & $(0.00)$ & 0.09 & $(0.09)$ & 0.22 & $(0.20)$ \\
\hline \multirow[t]{2}{*}{ Sum of PUFA } & Yc & 0.38 & $(0.11)$ & 0.26 & $(0.07)$ & 0.33 & $(0.04)$ & 0.28 & $(0.06)$ \\
\hline & EBV & 2.28 & $(0.28)$ & 0.75 & $(0.44)$ & 0.35 & $(0.20)$ & 0.64 & $(0.36)$ \\
\hline \multirow[t]{2}{*}{ PUFA/SFA } & Yc & 2.65 & $(2.56)$ & 0.15 & $(0.09)$ & 0.15 & $(0.09)$ & 0.16 & $(0.08)$ \\
\hline & EBV & 2.35 & $(0.61)$ & 2.44 & $(0.69)$ & 1.41 & $(0.42)$ & 2.45 & $(0.70)$ \\
\hline
\end{tabular}

Yc phenotype adjusted for fixed effects, EBV estimated breeding value, SFA saturated fatty acid, n-3 and n- 6 total of omega 3 and 6 fatty acids respectively, n- $6 / n-3$ ratio of omega 6 to omega 3 fatty acids, PUFA Polyunsaturated fatty acid, PUFA/SFA ratio of polyunsaturated to saturated fatty acid.

C14:0 for being the most harmful to health, C16:0, and sum of SFA. In order to increase the concentration of MUFA, such as C18:1 and C18:1 $\mathrm{n}-7$, as a result of its biological importance as precursors of PUFA and because of its importance on human health, the SNP-BLUP method is the most appropriate in this context. For n-3 acids, such as C20:3 n-3, the accuracies were low, however, its function in cell function regulation, decreased triglycerides blood levels, anti-inflammatory response, among others factors, need further studies to determine the most suitable method for genomic prediction.

Recently, the European Union established a new legislation (Regulation (EU) No 1169/2011) on the provision of food information to consumers. In this new regulation established that is mandatory specify information about food chemical composition, such as the amounts of fat, saturates, monounsaturated, polyunsaturated, carbohydrate, sugars, protein and salt. Similarly, in United States, the Food Safety and Inspection Service (FSIS) developed a compliance guideline to help the industry determine which statements are permitted on the labeling of their products and the criteria for their use, particularly for omega fatty acids from animal sources. All these regulations aimed to give more detailed information to consumer about food chemical composition and potential impacts on human health. Moreover new and evolving food labeling legislation should protect the consumer from misleading claims about the health benefits of a food or any of its components. Although the beef fatty acid profile is not considered as selection criteria in beef cattle breeding programs, due to the high cost to obtain the phenotype and analyses' operating cost, is important that the breeders have alternative tools to improve the beef fatty acid composition in view of the greater demand of consumers.

Despite the prediction accuracies were not very high, the use of genomic information to predict genomic values for beef FA profile in breeding animals is a feasible alternative, with a reasonable cost, to contribute for meat quality improvement. In addition, for commercial herds the results of this study would give support to make better management decision within the farm in order to achieve different niche of markets. This would help the farmers to meet the requirements to participate in a special meat certification programs (prime beef cuts) that bonus for higher meat quality, for example beef fatty acid composition. Despite the large differences among the studied methods, the SNP-BLUP method is a worthwhile alternative for application in genomic evaluations on a large scale, considering the low computational requirement time and the similarity of the results obtained with the Bayesian methods.

\section{Conclusions}

Beef FA profile is a very important study area due to its implication in human health. Genomic information can assist in improving FA profile in Zebu animals, since the use of genomic information yielded genomic values for FA profile with accuracies ranging from low to moderate. None of the methods excelled in terms of accuracy, however, the SNPBLUP method allows obtaining less biased genomic evaluations, thereby; this method is more feasible when taking account the computational cost. Despite the lowest bias observed for EBV, the adjusted phenotype is the preferred pseudophenotype considering the genomic prediction accuracies regarding the context of the present study.

\section{Acknowledgements}

This work was supported by Fundação de Amparo à Pesquisa do Estado de São Paulo (FAPESP) with grant numbers (\#2011/2141-0 and \#2009/16118-5).

\section{References}

Aboujaoude, C., Pereira, A. S. C., Feitosa, F. L. B., de Lemos, M. V. A., Chiaia, H. L. J., Berton, M. P., ... Baldi, F. (2016). Genetic parameters for fatty acids in intramuscular fat from feedlot-finished Nellore carcasses. Animal Production Science. http://dx.doi.org/10. 1071/AN16107.

Boddhireddy, P., Kelly, M. J., Northcutt, S., Prayaga, K. C., Rumph, J., \& De Nise, S. (2014) Genomic predictions in Angus cattle: Comparisons of sample size, response variables, and clustering methods for cross-validation. Journal of Animal Science, 92, 485-497.

Bolormaa, S., Pryce, J. E., Kemper, K., Savin, K., Hayes, B. J., Barendse, W., ... Goddard, M. E (2013). Accuracy of prediction of genomic breeding values for residual feed intake and carcass and meat quality in Bos taurus, Bos indicus, and composite beef cattle. Journal of Animal Science, 91, 3088-3104.

Bressan, M. C., Rossato, L. V., Rodrigues, E. C., Alves, S. P., Bessa, R. J. B., Ramos, E. M., \& Gama, L. T. (2011). Genotype $\times$ environment interactions for fatty acid profiles in and finished on pasture or grain. Journal of Animal Science, 89, 221-232.

Cesar, A. A., Regitano, L. C. Mourão, G. B., Tullio, R. R., Lanna, D. P., Nassu, R. T. .... Coutinho, L. L. (2014). Genome-wide association study for intramuscular fat deposition and composition in Nellore cattle. BMC Genetics, 15, 1-15.

Clark, S. A., Hickey, J. M., \& van der Werf, J. H. (2011). Different models of genetic variation and their effect on genomic evaluation. Genetics Selection Evolution, 43, 18.

Colombani, C., Legarra, A., Fritz, S., Guillaume, F., Croiseau, P., Ducrocq, V., \& Robert-Granié, C. (2013). Application of Bayesian least absolute shrinkage and selection operator (LASSO) and BayesC $\pi$ methods for genomic selection in French Holstein and Montbéliarde breeds. Journal of Dairy Science, 96, 575-591.

Daetwyler, H. D., Pong-Wong, R., Villanueva, B., \& Woolliams, J. A. (2010). The impact of genetic architecture on genome-wide evaluation methods. Genetics, 185, 1021-1031.

Daetwyler, H. D., Calus, M. P. L., Pong-Wong, R., De Los Campos, G., \& Hickey, J. M. (2013) Genomic prediction in animals and plants: Simulation of data, validation, reporting, and benchmarking. Genetics, 193, 347-365.

De Los Campos, G., Naya, H., Gianola, D., Crossa, J., Legarra, A., Manfredi, E., ... Cotes, J. M (2009). Predicting quantitative traits with regression models for dense molecular markers and pedigree. Genetics, 182, 375-385.

De Los Campos, G., Hickey, J. M., Pong-Wong, R., Daetwyler, H. D., \& Calus, M. P. L. (2013). Whole-genome regression and prediction methods applied to plant and animal breeding. Genetics, 193, 327-345.

Ekine-Dzivenu, C., Chen, L., Vinsky, M., Aldai, N., Dugan, M. E. R., McAllister, T. A., ... Li, C. (2013). Estimates of genetic parameters for fatty acids in brisket adipose tissue of Canadian commercial crossbred beef steers. Meat Science, 96, 1517-1526.

Feitosa, F. L. B., Olivieri, B. F., Aboujaoude, C., Pereira, A. S. C., Lemos, M. V. A., Chiaia, H. L. M., ... Baldi, F. (2016). Genetic correlation estimates between beef fatty acid profile with meat and carcass traits in Nellore cattle finished in feedlot. Journal of Applied Genetics. http://dx.doi.org/10.1007/s13353-016-0360-7.

Fernandes Júnior, G. A. F., Rosa, G. J., Valente, B. D., Carvalheiro, R., Baldi, F., Garcia, D. A., .. Albuquerque, L. G. (2016). Genomic prediction of breeding values for carcass traits in Nellore cattle. Genetics Selection Evolution, 48, 7.

Folch, J., Lees, M., \& Stanley, G. H. A. (1957). Simple method for the isolation and purification of lipids from animal tissues. The Journal of Biological Chemistry, 226, 497-509.

French, P., O'Riordan, E. G., \& Monahan, F. J. (2000). Meat quality of steers finished on autumn grass, grass silage or concentrate-based diets. Meat Science, 56, 173-180.

Garrick, J. D. (2011). The nature, scope and impact of genomic prediction in beef cattle in the United States - Review. Genetics Selection Evolution, 47, 1-11. 
Ip, C. (1997). Review of the effects of trans fatty acids, oleic acid, n-3 polyunsaturated fatty acids, and conjugated linoleic acid on mammary carcinogenesis in animals. The American Journal of Clinical Nutrition, 66, 1523-1529.

Katan, M. B., Zoock, P. M., \& Mensink, R. P. (1994). Effects of fats and fatty acids on blood lipids in humans: An overview. The American Journal of Clinical Nutrition, 60, 1017-1022.

Kelly, M. J., Tume, R. K., Newman, S., \& Thompson, J. M. (2013). Genetic variation in fatty acid composition of subcutaneous fat in cattle. Animal Production Science, 53 129-133.

Kizilkaya, K., Fernando, R. L., \& Garrick, D. J. (2010). Genomic prediction of simulated multibreed and purebred performance using observed fifty thousand single nucleotide polymorphism genotypes. Journal of Animal Science, 88, 544-551.

Kramer, J. K. G., Fellner, V., Dugan, M. E. R., Sauer, F. D., Mossoba, M. M., \& Yurawecz, M. P. (1997). Evaluating acid and base catalysts in the methylation of milk and rumen and rumen fatty acids with special emphasis on conjugated dienes and total trans fatty acids. Lipids, 32, 1219-1228.

Lawrie, R. A. (2005). Ciência da carne (6 ed.). Porto Alegre: Artmed (384 p).

Legarra, A. (2014). Bases for Genomic Prediction. Course on Genomic Selection. v0.9. (pp. 1-75), 1-75 (http://snp.toulouse.inra.fr/ alegarra/, Accessed 04 Feb 2015).

Legarra, A., Robert-Granié, C., Manfredi, E., \& Elsen, J. M. (2008). Performance of genomic selection in mice. Genetics, 180, 611-618.

Legarra, A., Granie, C. R., \& Croiseau, P. (2011). Improved Lasso for genomic selection. Genetics Research, 93, 77-87.

Legarra, A., Ricard, A., \& Filangi, O. (2013). GS3: Genomic Selection, Gibbs Sampling, Gauss Seidel (and BayesC $\pi$ ). (http://snp.toulouse.inra.fr/ alegarra/, Accessed 03 Feb 2015).

Lock, A. L., Horne, C. A., Bauman, D. E., \& Salter, A. M. (2005). Butter naturally enriched in conjugated linoleic acid and vaccenic acid alters tissue fatty acids and improves the plasma lipoprotein profile in cholesterol-fed hamsters. The Journal of Nutrition, 135 , 1934-1939.

Lund, M. S., Sahana, G., Koning, D., Su, G., \& Carlborg, O. (2009). Comparison of analyses of the QTLMAS XII common dataset. I: Genomic selection. BMC proceedings. BioMed Central. 3. (pp. 1).

Menezes, L. F. G., Restle, J., Brondani, I. L., Kozloski, G. V., Deschamps, F., \& Sachet, R. H. (2009). Perfil de ácidos graxos na carne de novilhos Charolês e Nelore puros e de gerações avançadas do cruzamento rotativo, terminados em confinamento. Cienc. Rural, 39, 2478-2484.

Meuwissen, T. H., Hayes, B. J., \& Goddard, M. E. (2001). Prediction of total genetic value using genome-wide dense marker map. Genetics, 157, 1819-1829.

Morota, G., Boddhireddy, P., Vukasinovic, N., Gianola, D., \& Denise, S. (2014). Kernel-based variance component estimation and whole-genome prediction of pre-corrected phenotypes and progeny tests for dairy cow health traits. Frontiers in Genetics, 5, 56.

Moser, G., Tier, B., Crump, R. E., Khatkar, M. S., \& Raadsma, H. W. (2009). A comparison of five methods to predict genomic breeding values of dairy bulls from genome-wide SNP markers. Genetics, Selection, Evolution, 41, 56.

Neves, H. H., Carvalheiro, R., O'Brien, A. M. P., Utsunomiya, Y. T., do Carmo, A. S., Schenkel, F. S., ... Garcia, J. F. (2014). Accuracy of genomic predictions in Bos indicus (Nellore) cattle. Genetics Selection Evolution, 46, 17.

Onogi, A., Ogino, A., Komatsu, T., Shoji, N., Shimizu, K., Kurogi, K., ... Iwata, H. (2015). Whole-genome prediction of fatty acid composition in meat of Japanese Black cattle. Animal Genetics, 46, 557-559.

Park, T., \& Casella, G. (2008). The Bayesian lasso. Journal of the American Statistical Association, 103, 681-686.

Perry, D., Nicholls, P. J., \& Thompson, J. M. (1998). The effect of sire breed on the melting point and fatty acid composition of subcutaneous fat in steers. Journal of Animal Science, 76, 87-95.
Pensel, N. (1998). The future of red meat in human diets. Nutrit. Abstrac. Rev., 68, 1-4 (Series A), Farnham Royal.

Pitchford, W. S., Deland, M. P. B., Siebert, B. D., Malau-Aduliand, A. E. O., \& Bottema, C. D. K. (2002). Genetic variation in fatness and fatty acid composition of crossbred cattle. Journal of Animal Science, 80, 2825-2832.

Prado, I. N., Moreira, F. B., Matsushita, M., \& Souza, N. E. (2003). Longissimus dorsi fatty acids composition of Bos indicus and Bos indicus $\times$ Bos taurus crossbred steers finished in pasture. Brazilian Archives of Biology and Technology, 46, 601-608.

Resende, M. D. V., Lopes, P. S., da Silva, R. L., \& Pires, I. E. (2008). Seleção genômica ampla (GWS) e maximização da eficiência do melhoramento genético. Pesqui. Florest. Bras., $56,63-77$.

Rossato, L. V., Bressan, M. C., Rodrigues, E. C., Carolino, M. D. C., Bessa, R. J. B., \& Alves, S. P. P. (2009). Composição lipídica de carne bovina de grupos genéticos taurinos e zebuínos terminados em confinamento. Revista Brasileira de Zootecnia, 38, $1841-1846$

Rossato, L. V., Bressan, M. C., Rodrigues, E. C., Gama, L. T., Bessa, R. J. B., \& Alves, S. P. A. (2010). Parâmetros físico-químicos e perfil de ácidos graxos da carne de bovinos Angus e Nelore terminados em pastagem. Revista Brasileira de Zootecnia, 39, $1127-1134$

Rule, D. C. (1997). Direct transesterification of total fatty acids of adipose tissue, and of freeze-dried muscle and liver with boron-trifluoride in methanol. Meat Science, 46, 23-32.

Saatchi, M., Garrick, D. J., Tait, R. G., Mayes, M. S., Drewnoski, M., Schoonmaker, J., ... Reecy, J. M. (2013). Genome-wide association and prediction of direct genomic breeding values for composition of fatty acids in Angus beef cattle. BMC Genomics, 14, 730 .

Silva, R. G. D., Prado, I. N. D., Matsushita, M., \& Souza, N. E. D. (2002). Dietary effects on muscle fatty acid composition of finished heifers. Pesquisa Agropecuária Brasileira, 37, 95-101.

Silva, R. M. O.,Fragomeni, B. O., Lourenco, D. A. L., Magalhães, A. F. B., Irano, N., Carvalheiro, R., ... Albuquerque, L. G. (2016). Accuracies of genomic prediction of feed efficiency traits using different prediction and validation methods in an experimental Nellore cattle population. Journal of Animal Science, 94, 3613-3623.

Simopoulos, A. P. (2002). The importance of the ratio of omega-6/omega-3 essential fatty acids. Biomedicine E' Pharmacotherapy, 56, 365-379.

Smet, S., Raes, K., \& Demeyer, D. (2004). Meat fatty acid composition as affected by fatness and genetic factors: A review. Animal Research, 53, 81-98.

Tamminga, S., \& Doreau, M. (1991). Lipids and rumen digestion. In J. P. Jouany (Ed.), Rumen microbial metabolism and ruminant digestion (pp. 151-164). Paris: Institut National de la Recherche Agronomique.

Tapiero, H., Nguyen-Ba, G., Couvreur, P., \& Tew, K. D. (2002). Polyunsaturated fatty acids and eicosanoids in human health and pathologies. Biomedicine E Pharmacotherapy, 56, 215-222.

Tibshirani, R. (1996). Regression shrinkage and selection via the lasso. Journal of the Royal Statistical Society, 58, 267-288.

Wiggans, G. R., Vanraden, P. M., \& Cooper, T. A. (2011). The genomic evaluation system in the United States: Past, present, future. Journal of Dairy Science, 94, 3202-3211.

Wood, J. D., \& Enser, M. (1997). Factors influencing fatty acids in meat and the role of antioxidants in improving meat quality. British Journal of Nutrition, 78, 49-60.

Woollett, A. L., Spady, K. D., \& Dietschy, M. J. (1992). Saturated and unsaturated fatty acids independently regulate low-density lipoprotein receptor activity and production rate. Journal of Lipid Research, 33, 77-88. 